\title{
Hersenactiviteit tijdens een paniekaanval
}

Neurofysiologische veranderingen tijdens een paniekaanval bij een man met agorafobie."

Guevara, H.A. ${ }^{1,3}$, Keeser, D. ${ }^{4}$, Verhagen-Schouten, S. ${ }^{3}$, Stobbe-Meijers, M.A. ${ }^{3}$, Promes, V.H.L. ${ }^{3}$, Deijen, J.B. ${ }^{2}$, Engelbregt H.J. ${ }^{3,4}$

${ }^{1}$ Adagio, Amsterdam

${ }^{2}$ Vrije Universiteit, Afdeling Klinische Neuropsychologie, Amsterdam

${ }^{3}$ Hersencentrum, Amsterdam

${ }^{4}$ Ludwig-Maximilian Universiteit, München, Duitsland

Correspondentieadres:

andres@adagioamsterdam.nl

\section{Samenvatting}

De heer V. (V.) lijdt sinds zijn jeugd onder een specifieke fobie met paniekstoornis. De paniek start wanneer hij de grenzen van zijn woonplaats bereikt, onafhankelijk van het type vervoer waarmee hij reist. Ook speelt de bestemming geen rol in het ontstaan of de ernst van de paniekaanval. Tijdens een autorit die een paniekaanval uitlokte zijn EEG opnames gemaakt. bèta activiteit (van 13-30 Hz.) bleek over grote delen van de cortex toe te nemen tijdens de paniekaanval. Verder was sprake van relatief plotselinge afname van delta en theta activiteit (1-8 Hz) over vrijwel de gehele cortex tijdens de paniekaanval. 


\section{Inleiding}

De heer V. (V.) meldt zich begin 2008 aan met angstklachten en geheugenproblemen. Hij is dan 47 jaar oud, heeft geen kinderen en is samenwonend met zijn vriendin. Hij heeft een gemiddeld opleidingsniveau en werkt zelfstandig in de machinebouw. Bij binnenkomst is hij reeds gediagnosticeerd met een angststoornis (agorafobie met paniekaanvallen sinds ruim 20 jaar). Meer specifiek ontstaan de paniekaanvallen bij het verlaten van zijn woonplaats, onafhankelijk van de wijze van vervoer. Verder ervaart hij in zijn dagelijkse leven spanningsklachten en dit uit zich volgens zijn familie ook in het contact met zijn omgeving. Hij reageert dan bijvoorbeeld geprikkeld wanneer hij ergens op moet wachten. Sinds ongeveer 15 jaar neemt hij Lorazepam en Paroxetine in, die hem zijn voorgeschreven in verband met langdurige stemmingsklachten en de agorafobie.

In verband met de chroniciteit en verergering van de symptomen gaat V. naar zijn huisarts waarna zij hem verwijst naar een neuropsycholoog voor psychotherapie. Hoewel V. en familie een verbetering waarnemen op het gebied van sociale omgang en vermindering van spanningsklachten, nemen de klachten met betrekking tot de agorafobie niet af. Om nader inzicht te verkrijgen in de achtergrond van zijn klachten verzoekt V. om een EEG opname te maken tijdens een exposure-in-vivo sessie, te weten een autorit. Na zorgvuldig overleg in ons team besluiten wij het onderzoek uit te voeren. Een vertrouwenspersoon van V. bestuurt de auto waarin V. achterin plaatsneemt en via een electrodenkap is verbonden aan het mobiele EEG apparaat.

\subsection{EEG bij paniekstoornissen}

Er is relatief weinig geschreven over EEG bij paniekstoornissen, al dan niet met agorafobie. Gordeev beschreef patronen en auditieve event related potentials (ERP, EEG veranderingen als gevolg van een gebeurtenis) van het EEG in rustconditie bij een groep van 77 mensen met een paniekstoornis (Gordeev, 2008). De auteur maakte hierbij een vergelijking met een groep van 28 mensen zonder deze aandoening. Bij de groep met een paniekstoornis met agorafobie vond hij lagere P300 waardes na de ERP's. Tevens werd een significante verlaging gemeten van alfa $(\alpha)$ activiteit en een significante verhoging van bèta $(\beta)$ activiteit in de rechterhemisfeer. De groep met een paniekstoornis, maar zonder agorafobie 
had een significante verhoging van theta

$(\theta)$ activiteit in de linker temporaal gebieden. Deze afwijkingen bij de twee groepen met paniekstoornissen zouden respectievelijk wijzen op een verhoogde activiteit in de opstijgende baan (ascending) van de mesencephalische reticulaire formatie en verhoogde activiteit in de limbische structuren. De vraag is hoe specifiek de diagnose is bij de betreffende onderzoeksgroep aangezien Keeser et al. vergelijkbare resultaten vonden bij een groep mensen met ernstige depressie (Keeser et al., 2013).

Lopes et. al. (Lopes et al., 2010) wekten paniekaanvallen op door een groep van 15 mensen met een paniekstoornis een relatieve verhoging van $\mathrm{CO} 2(35 \%)$ toe te dienen tijdens EEG opname. De kwantitatieve EEG gegevens (qEEG) tijdens de paniekaanval (bij 12 mensen slaagde de $\mathrm{CO} 2$ procedure) werden afgetrokken van de qEEG gegevens in de rustconditie. Tijdens de paniekaanval werd rechts temporaal (T4 volgens internationale 10-20 EEG systeem) een relatieve verhoging van $\beta$ activiteit gemeten. Rechtsfrontaal (F4) werd een verhoging van alfa activiteit gevonden en links temporaal (T5) werd een verlaging gevonden van relatieve $\theta$ activiteit. Kara en
Polo beschrijven in een overzichtsartikel, gebaseerd op 3 artikelen (Engelbregt, Keeser, Promes, Verhagen-Schouten, \& Deijen, 2012; Hayashi, Makino, Hashizume, Nakano, \& Tsuboi, 2010; Lopes et al., 2010) dat het rusttoestand EEG van mensen met paniekstoornis herhaald versterkte pariëtale en occipitale theta activiteit vertoond, terwijl tijdens de paniekaanval een relatieve verlaging optreed van theta activiteit over de hele cortex, in combinatie met verhoging van rechtsfrontale alfa activiteit en rechts temporale beta activiteit. in combinatie met verhoogde beta activiteit over de gehele cortex (Kara \& Polo, 2014). In een ander overzichtsartikel, van Wenzel en Pogarell (Schicho \& Pogarell, 2014) wordt beschreven dat er geen specifieke EEG factoren kunnen worden aangewezen bij mensen die lijden aan paniekaanvallen maar dat er wel kan worden gesteld dat het EEG beeld afwijkend is ten opzichte van een EEG beeld bij gezonde personen. In andere woorden, er is op basis van de door hen bestudeerde literatuur geen sprake van een typisch EEG fenotype voor het voorspellen van paniekaanvallen. Ten tweede komen zij tot de conclusie dat paniekklachten die onbehandelbaar zijn middels psychotherapie mogelijk kunnen 
verminderen door toediening van antiepileptica.

Zoals aangegeven is naar EEG bij paniekaanvallen weinig onderzoek gedaan. Over het EEG bij angst in het algemeen is echter relatief veel literatuur te vinden. Een aantal onderzoeken hierover willen we graag benoemen. Knyazev et. al (Knyazev, Savostyanov, \& Levin, 2004) verdeelden de traditionele alfa frequenties (7,5-12,5 Hz.) in drie alfa subtypes ( $\alpha 1, \alpha 2$ en $\alpha 3$ ) voor iedere individuele deelnemer van hun onderzoek. Hun onderzoek laat zien dat de toename van angstgevoelens positief zijn gecorreleerd met lage-alfa activiteit en negatief met hoge alfa activiteit (tot 12,5 Hz.) Daarbij is sprake van een negatieve correlatie tussen $\delta$ en $\alpha 2$ activiteit. Een indirecte manier om angst te kunnen meten is via de testosteron en cortisol spiegel. Deze hormonen hebben respectievelijk een (bewuste) angst reducerende en angst verhogende werking. Schutter en van Honk (Schutter \& Honk, 2004) zagen een vermindering van deltabèta $(\delta-\beta)$ coherentie na de toediening van testosteron bij gezonde proefpersonen. Testosteron is het eindproduct van de hypothalamische-pijnappelklier-gonadale (HPG). In dit systeem heeft cortisol een antagonistische werking. In een andere studie van Schutter en van Honk (Schutter \& van Honk, 2005) werd dan ook een positieve relatie gevonden tussen toename van cortisol en $\delta$ - $\beta$ coherentie. Interessant in de theorievorming rondom $\delta-\beta$ is onderzoek van Putman (Putman, 2011). Hij liet mensen vragenlijsten invullen met betrekking tot angstgevoelen en gevaar vermijdend gedrag. Tevens werd er een EEG opname gemaakt in rustconditie. Hij vond een verminderde $\delta-\beta$ coherentie bij gevaar vermijdende mensen. Ook vond hij een verminderde $\delta-\beta$ coherentie vond bij meer angstige mensen. $\delta-\beta$ coherentie lijkt daardoor niet alleen meer een interessante maat voor het meten van angst als toestandsbeeld maar een relatief lage $\delta-\beta$ coherentie in het rust EEG zou derhalve een aanwijzing kunnen zijn voor een relatief angstige persoonlijkheid.

\subsection{De huidige studie}

Voorafgaand aan het huidige onderzoek heeft V. een langdurig traject van hulpverlening achter de rug. Diverse therapeuten hebben onder meer EMDR en cognitieve gedragstherapie gegeven. Daarbij is V. door diverse medische molens gegaan. Hij geeft aan dat er beeldvormende technieken zijn toegepast (bijvoorbeeld CT, EEG en MRI) en uitgebreide 
psychologische onderzoeken gedaan. Naast de indruk dat sprake is van een agorafobie met paniekstoornis werd in deze onderzoeken "niets gevonden". Rapportages van deze onderzoeken bleken niet in V.s' bezit.

Voor het onderhavige onderzoek is een mobiel EEG apparaat gebruikt om een opname te maken van de hersenactiviteit van $\mathrm{V}$. die als passagier tijdens een autorit voorbij de grenzen van zijn woonplaats. De specifieke fobie van V. is immers het verlaten van de grenzen van zijn gemeente. Tijdens deze rit werd constant EEG gemeten en V. gaf op een schaal van 0-10 elke minuut weer in hoeverre hij zich gespannen of angstig voelde. Omdat we voorafgaande aan het onderzoek niet exact wisten hoe de paniekaanval zich zou uiten werd uit veiligheidsoverwegingen afgesproken dat de opname bij een paniekscore van 8 zou worden afgebroken. Hierdoor verwachtten we dat de bestuurder de gelegenheid had om een parkeerplaats te vinden en terug te rijden. Het achterwege laten van de EEG opname tijdens de terugweg is afgesproken in verband met het opnieuw creëren van een comfortabele situatie. Een EEG kap op het hoofd wordt in het algemeen niet als comfortabel ervaren.
$\mathrm{Na}$ ongeveer een kilometer buiten de grenzen van zijn woonplaats (een rit van ongeveer 15 minuten) noteerde $\mathrm{V}$. een paniekscore van 8 . De bestuurder stopte de auto, na enkele minuten werd de EEG apparatuur opgeborgen en de terugreis werd aangevangen.

\section{Methode van onderzoek}

\subsection{Deelnemer}

De 47 jarige $V$. is door zijn huisarts verwezen voor het betreffende EEG onderzoek. Er was geen financiële vergoeding voor deelname aan het onderzoek. Het informed consent is mondeling overlegd, naderhand is door V. toestemming gegeven om de gegevens geanonimiseerd te verwerken voor publicatie.

\subsection{Meetinstrumenten en apparatuur}

Voor de EEG-metingen is een Deymed Truscan systeem met 32 kanalen gebruikt in combinatie met een electrodenkap van Electrocap International met 19 electroden. Dit systeem was aangesloten op een portable computer met een Windows besturings systeem.

V. en de EEG assistent zaten achterin een comfortabele personenauto. 
De EEG meting werd met behulp van het programma Insight II (Persyst, Versie 2004.11.22) gescreend op epileptiforme fenomenen. De kwantitatieve analyses die daarop volgden werden met behulp van Neuroguide (Versie 2.6.6) gedaan.

\subsection{Procedure}

Er was één continue meting met open ogen gedurende het autorijden. Op basis van V.s' scores op de afgesproken angstschaal werden tijdsmarkeringen aangebracht aan het digitale EEG. Markeringen waren: toename van angst, angstscore, start paniekaanval en stoppen van auto.

\subsubsection{EEG opstelling}

De heer V. en de EEG assistent namen achterin de auto plaats. V. rechts en de EEG assistent aan de linkerkant. De portable computer en het EEG apparaat lagen tussen beide in. Met de bestuurder is afgesproken dat deze geen bemoeienis zou hebben met de opnames. Echter, wanneer de EEG-assistent of de V. verzoeken om te stoppen of terug te rijden geeft hij daaraan gehoor.

\subsubsection{Selecties EEG}

EEG metingen werden voorafgaand aan kwantitatieve analyse door een neuroloog gescreend op epileptische activiteit en focale problematiek. Hiervan bleek geen sprake. Dataselectie voor kwantitatieve EEG analyse is gedaan door een neuropsycholoog. Deze data werden gecontroleerd door een onafhankelijke EEG expert.

De gehele opname duurde 27,5 minuten. In verband met artefacten in het EEG als gevolg van spierbewegingen is de totale tijd aan EEG welke is gebruikt voor de kwantitatieve analyse tijdens de paniekaanval 1:28 minuten en 2:43 minuten voorafgaande aan de aanval. Er is gekozen voor linked-ears montage

\subsubsection{EEG bewerkingen}

Individuele getransformeerde EEG selecties van periode 1 (dit is de periode voorafgaande aan de paniekaanval met een totale EEG selectie van 2:43 min. werden met periode 2 (tijdens de paniekaanval, met een EEG selectie van 1:03) vergeleken middels paired-sample $\mathrm{T}$ tests met behulp van Neuroguide 2.6.6 Normative Database (Thatcher, 1998). Hierbij werd per periode gekeken naar powerveranderingen van EEG frequenties tussen 0 en $50 \mathrm{~Hz}$.. De uitkomst van de T-tests wordt in Tabel 1 weergegeven in een significantie waarde (p-waarde). Er is tweezijdig getoetst en alle 
uitslagen beneden een $\alpha$ van 5 procent worden beschouwd als een significante afof toename. Ook werd gekeken naar de duur van cross spectrale phase lock tussen de $\delta$ (1-4 Hz.) en $\beta$ frequenties. Phase locking is het consistent vuren van een groep cellen. Wanneer meerdere groepen van cellen in gelijke fase vuren kan daaruit worden afgeleid dat sprake is van communicatie tussen deze groepen van neuronen. Phase lock is daarmee een vergelijkbaar principe als coherentie en de correlatie tussen de twee maten is hoog (Thatcher et. al, 2008). De $\beta$ frequenties werden hiervoor opgedeeld in vier subtypes; 12-15 Hz., 15-18 Hz., 18-25 Hz. en $25-30 \mathrm{~Hz}$.

Het EEG werd vervolgens met behulp van het LORETA-pakket v20150415 (http://www.uzh.ch/keyinst/loreta.htm) nader bekeken. LORETA is een computerprogramma waarmee grofweg een indicatie wordt gegeven van de neuronale bron van hersenactiviteit $(\mu \mathrm{V} /$ $\mathrm{mm} 2$ ) van elke voxel op $5 \mathrm{~mm}$ ruimtelijke resolutie in de Talairach / MNI-ruimte. Een gedetailleerde beschrijving van de sLORETA-methode wordt gegeven door Pascual-Marqui (Pascual-Marqui, 2002). De hoofdhuid-EEG werd gesegmenteerd in
2 s-segmenten en omgezet in crossspectrumbestanden voor het discrete frequentiebereik van 1-4 Hz, 4-8 Hz, 8$10,5 \mathrm{~Hz}, 10,5-13 \mathrm{~Hz}, 13-20 \mathrm{~Hz}$ en $20-30$ $\mathrm{Hz}$ met behulp van de sLORETAtransformatiematrix. De elektrostatische hoofdhuidactiviteit wordt vervolgens omgezet in gestandaardiseerde stroomdichtheid in de cortex. Voor het statistisch vergelijken van de periode voorafgaande aan de paniek en het EEG tijdens de paniekaanval zijn drie artefactvrije delen van het EEG voor beide condities geselecteerd. In verband met de kleine steekproefgrootte, werd rekening gehouden met de variabiliteit van structureel hersenweefsel en geleidingsvermogen door middel van datanormalisatie. De statistische vergelijkingen werden uitgevoerd met behulp van de geïmplementeerde statistische niet-parametrische mappingtool. Het statistische niveau werd ingesteld op $\mathrm{p}<0,05$.

\section{Resultaten *}

Hieronder volgt een overzicht van de uitkomsten van de statistische analyse van de EEG-data voor de verschil van de power tussen de periode voorafgaande aan 
de paniekaanval en de paniek periode (Tabel 1). Met de power wordt bedoeld de wortel van de gekwadrateerde amplitude van de frequentie. Op deze manier kan de power alleen positieve waarden aannemen (Thatcher, 1998).

In Tabel 1 wordt een onderscheid gemaakt tussen de volgende bandbreedtes van spectraal EEG power. Delta ( $\delta$ 1-4 Hz.), Theta ( $\theta$ 4-8 Hz.), Alfa ( $\alpha$ 8-12 Hz.), Beta $(\beta$ 12-25 Hz), Beta $2(\beta 22530 \mathrm{~Hz})$.

\begin{tabular}{|l|l|l|l|l|l|}
\hline Tabel 1 & $\begin{array}{l}\text { Delta } \\
1-4\end{array}$ & $\begin{array}{l}\text { Theta } \\
4-8\end{array}$ & $\begin{array}{l}\text { Alpha } \\
8-12\end{array}$ & $\begin{array}{l}\text { Bèta } \\
12-25\end{array}$ & $\begin{array}{l}\text { High } \\
\text { Bèta } \\
25-30\end{array}$ \\
& Hz & Hz & Hz & Hz \\
\hline FP1-CSD & $\mathbf{0 , 0 0 0}$ & $\mathbf{0 , 0 0 0}$ & $\mathbf{0 , 0 0 1}$ & 0,376 & 0,738 \\
FP2-CSD & $\mathbf{0 , 0 0 1}$ & $\mathbf{0 , 0 0 9}$ & 0,054 & 0,506 & 0,206 \\
F3-CSD & $\mathbf{0 , 0 0 0}$ & $\mathbf{0 , 0 0 1}$ & 0,109 & 0,226 & 0,084 \\
F4-CSD & $\mathbf{0 , 0 0 0}$ & 0,059 & 0,258 & 0,261 & $\mathbf{0 , 0 0 2}$ \\
C3-CSD & $\mathbf{0 , 0 0 0}$ & $\mathbf{0 , 0 0 0}$ & 0,893 & 0,903 & $\mathbf{0 , 0 2 5}$ \\
C4-CSD & $\mathbf{0 , 0 0 1}$ & $\mathbf{0 , 0 1 0}$ & 0,400 & 0,889 & 0,285 \\
P3-CSD & $\mathbf{0 , 0 0 2}$ & 0,887 & 0,066 & 0,096 & $\mathbf{0 , 0 4 5}$ \\
P4-CSD & 0,154 & $\mathbf{0 , 0 4 9}$ & 0,620 & 0,195 & 0,636 \\
O1-CSD & 0,064 & $\mathbf{0 , 0 4 5}$ & 0,727 & $\mathbf{0 , 0 0 0}$ & $\mathbf{0 , 0 0 1}$ \\
O2-CSD & $\mathbf{0 , 0 3 0}$ & $\mathbf{0 , 0 0 3}$ & 0,235 & $\mathbf{0 , 0 0 0}$ & 0,102 \\
F7-CSD & $\mathbf{0 , 0 0 0}$ & $\mathbf{0 , 0 2 7}$ & 0,114 & 0,091 & 0,068 \\
F8-CSD & $\mathbf{0 , 0 3 4}$ & $\mathbf{0 , 0 0 4}$ & $\mathbf{0 , 0 1 5}$ & 0,385 & 0,895 \\
T3-CSD & 0,155 & 0,442 & 0,181 & $\mathbf{0 , 0 0 2}$ & $\mathbf{0 , 0 0 1}$ \\
T4-CSD & 0,061 & 0,252 & 0,489 & 0,229 & 0,586 \\
T5-CSD & 0,146 & 0,871 & 0,247 & $\mathbf{0 , 0 0 0}$ & $\mathbf{0 , 0 0 0}$ \\
T6-CSD & $\mathbf{0 , 0 0 1}$ & $\mathbf{0 , 0 0 1}$ & 0,898 & $\mathbf{0 , 0 3 5}$ & 0,428 \\
Fz-CSD & $\mathbf{0 , 0 0 5}$ & $\mathbf{0 , 0 0 0}$ & 0,275 & 0,190 & $\mathbf{0 , 0 1 2}$ \\
Cz-CSD & $\mathbf{0 , 0 0 0}$ & $\mathbf{0 , 0 0 0}$ & 0,297 & 0,068 & $\mathbf{0 , 0 0 2}$ \\
Pz-CSD & 0,265 & 0,079 & 0,449 & $\mathbf{0 , 0 0 0}$ & 0,386 \\
\hline significante & significante \\
verlaging & & verhoging \\
\hline
\end{tabular}

Tabel 1: Uitkomst van paired sample T-test. Er is gebruik gemaakt van Laplacian montage (referentie is het gemiddelde van de overige electroden). $\mathrm{Er}$ is tweezijdig getoetst, alle uitslagen beneden een $\alpha$ van 5 procent worden beschouwd als een significant verschil tussen het EEG voorafgaande en tijdens de paniekaanval. Blauwgekleurde cellen geven significant verlaagde activiteit weer tijdens de paniekaanval ten opzichte van ervoor. Verhoogde activiteit tijdens de paniekaanval wordt in zalmkleurige cellen weergegeven.

Er zijn significante toenames van $\beta$ activiteit, vooral posterieur. Daarbij is er over de gehele cortex een significante afname van $\theta$ activiteit tijdens de paniekaanval. Er werden in het huidige onderzoek geen verschillen gevonden tussen de duur van de $\delta-\beta$ phase lock tijdens en voorafgaande aan de paniekaanval.

sLORETA analyse geeft indicatie voor veranderende hersenactiviteit voor de volgende frequenties in de volgende gebieden tijdens de paniekaanval. De spatiële resolutie van sLORETA berekeningen op basis van 19 kanaals EEG is relatief laag. Derhalve zijn de bijgenoemde Brodmann Areas (BA) en specifieke benamingen van hersengebieden geen absolute realiteit maar een indicatie. 
- $\delta$; afname $(\mathrm{P}<.01)$ Parieto-frontaal; BA 3, 4 en 6.

- $\quad \theta$; afname $(\mathrm{P}<.01)$ Frontaal; BA 8 .

- $\quad \alpha 1(8-10,5$ Hz. $)$; afname $(\mathrm{P}<.01)$ Frontaal, BA 47, Inferior frontal Gyrus.

- $\quad \alpha 2(10,5-13$ Hz. $)$; afname $(\mathrm{P}<.01)$;
Frontaal, BA 11, rectal Gyrus en $\alpha 2$; toename $(\mathrm{P}<.05)$; BA 37, Fusiform Gyrus $(\mathrm{P}<.05)$.

- $\quad \beta 1$ (13-20 Hz.); toename $(\mathrm{P}<.01)$; Parietaal, BA 40.

- $\quad \beta 2$ (20-30 Hz.; toename Parietaal, BA 37, Fusiform Gyrus.

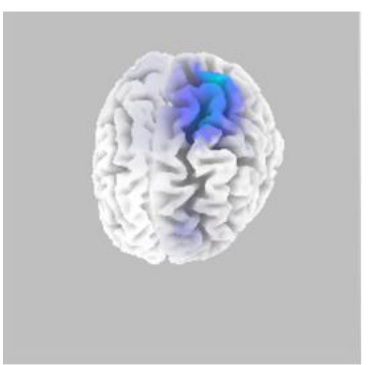

1-4 Hz Delta activiteit

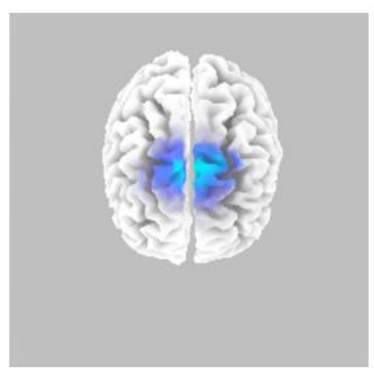

4-8 Hz. Theta activiteit

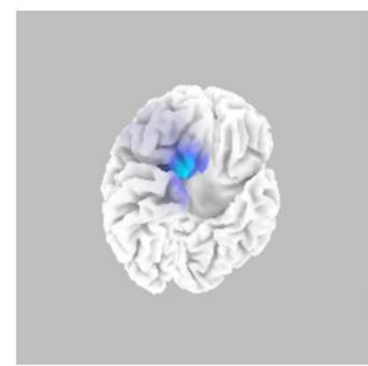

8-10.5 Hz. Alfa activiteit

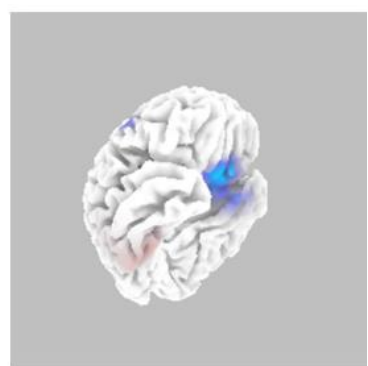

10.5-13 Hz. Alfa activiteit

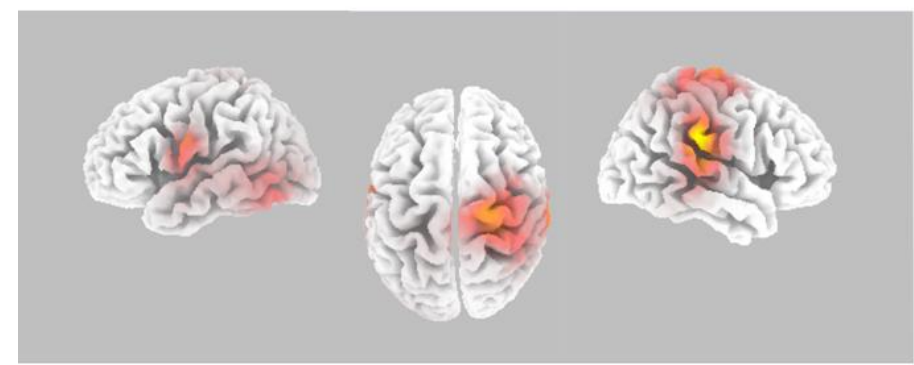

13-20 Hz. Beta activiteit

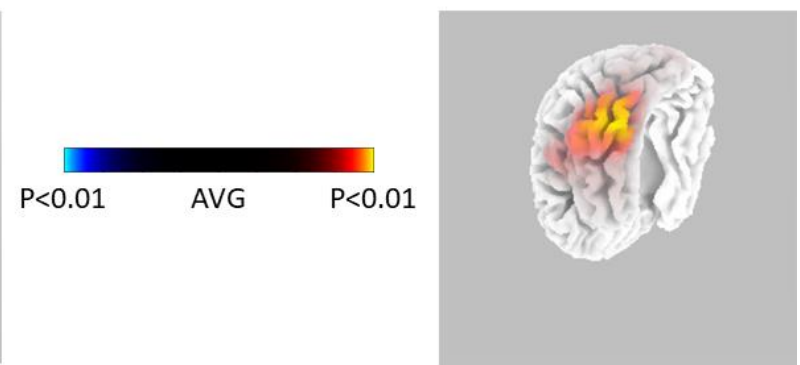

20-30 Hz. Beta activiteit

Figuur 2: Het Eeg tijdens de paniekaanval minus het EEG voorafgaande aan de paniekaanval. Afgebeeld zijn respectievelijk Delta, Theta, Alfa 1 en 2 en Beta 1 en 2 activiteit.

\section{Discussie}

\subsection{Bruikbaarheid en ethische} kanttekeningen bij het huidige onderzoek

In deze studie wordt het EEG van een 47 jarige man gemeten vóór en tijdens het doormaken van een paniekaanval. Een ethische vraag die rijst bij een dergelijk onderzoek is of het verantwoord is, of tenminste in het belang van de betreffende persoon, om een paniekaanval te forceren. 
Binnen het onderzoeksteam was er twijfel over zowel de haalbaarheid als het nut van deze exposure. De beslissing om in te stemmen met de vraag van $\mathrm{V}$. en familie is genomen na uitgebreide bestudering van zijn dossier en een psychotherapietraject met beperkt resultaat. V. rapporteerde weliswaar enige verbetering in zijn dagelijks functioneren en stemming na deze therapie maar er bleek geen verschil te zijn in de ernst van zijn aanmeldklacht.

De langdurige medicamenteuze behandeling ( $>15$ jaar) heeft ook minimale verbetering van zijn situatie opgeleverd. V. heeft vooraf uitgebreid beschreven hoe het verloop van zijn paniekaanvallen in het algemeen is. Op basis hiervan meenden wij een inschatting te kunnen maken van het risico dat ermee gepaard ging voor de gezondheid van $\mathrm{V}$. en de veiligheid van alle inzittenden in het voertuig tijdens de opname. Wellicht kan meer inzicht in EEG veranderingen tijdens een paniekaanval nuttig zijn bij het ontwikkelen van nieuwe behandelprotocollen.

\subsection{Conclusie en aanbevelingen}

Uit huidig onderzoek gebleken dat er veranderingen plaatsvinden in het EEG van een volwassen man met paniekaanval met agorafobie. Vooral $\beta$ activiteit in het spectrum van 13-30 Hz. in het centrale gedeelte van cortex neemt toe. Daarbij werd tijdens het doormaken van de paniekaanval een afname van $\delta$ en $\theta$ activiteit gemeten over de gehele cortex. Dit sluit aan op de bevindingen van eerder onderzoek, waarbij toename van $\theta$ activiteit werd gerapporteerd bij mensen met angstklachten bij gevoelens van ontspanning (zie bijvoorbeeld (Suetsugi et al., 2000)). Ook bij V. is het rust EEG door ons geregistreerd. In vergelijking met een normatieve database (Thatcher, 1998) was de 13-26 Hz. $\beta$ activiteit al verhoogd voorafgaande aan de paniekaanval. De verhoogde activiteit nam nog verder toe tijdens de paniekaanval. EEG kan derhalve indicatief zijn voor het risico op een paniekaanval. Iemand met een EEG beeld dat sterk overeenkomt met het beeld dat je tijdens een paniekaanval kunt verwachten heeft mogelijk minder stressoren nodig om een paniekaanval te forceren.

* Gebaseerd op eerder gepubliceerde data (Engelbregt et al., 2012) 


\section{Literatuur}

Engelbregt, H. J., Keeser, D., Promes, V. H., Verhagen-Schouten, S., \& Deijen, J. B. (2012). In-vivo EEG Changes During A Panic Attack in A Patient With Specific Phobia. Journal of Medical Cases, 3(1), 3438 .

Gordeev, S. (2008). Clinicalpsychophysiological studies of patients with panic attacks with and without agoraphobic disorders. Neuroscience and behavioral physiology, 38(6), 633-637.

Hayashi, K., Makino, M., Hashizume, M., Nakano, K., \& Tsuboi, K. (2010). Electroencephalogram abnormalities in panic disorder patients: a study of symptom characteristics and pathology. BioPsychoSocial medicine, 4(1), 9.

Kara, O., \& Polo, O. (2014). Autonomic and central stress-regulation disintegration in stress-related anxiety disorders. Acta Neuropsychologica, 12(1).

Keeser, D., Karch, S., Davis, J., Surmeli, T., Engelbregt, H., Länger, A., . . . Thatcher, R. (2013). Changes of resting-state EEG and functional connectivity in the sensor and source space of patients with major depression. Klinische Neurophysiologie, 44(01), P142.

Knyazev, G. G., Savostyanov, A. N., \& Levin, E. A. (2004). Alpha oscillations as a correlate of trait anxiety. International journal of psychophysiology, 53(2), 147-160.

Lopes, F. L., Oliveira, M. M., Freire, R. C., Caldirola, D., Perna, G., Bellodi, L., . . . Ribeiro, P. (2010). Carbon dioxide-induced panic attacks and quantitative electroencephalogram in panic disorder patients. The
World Journal of Biological

Psychiatry, 11(2-2), 357-363.

Pascual-Marqui, R. D. (2002).

Standardized low-resolution brain electromagnetic tomography (sLORETA): technical details. Methods Find Exp Clin Pharmacol, 24(Suppl D), 5-12.

Putman, P. (2011). Resting state EEG delta-beta coherence in relation to anxiety, behavioral inhibition, and selective attentional processing of threatening stimuli. International journal of psychophysiology, 80(1), 63-68.

Schicho, W., \& Pogarell, O. (2014).

Physiological Aberrations in Panic

Disorder Electrophysiology and Psychophysiology in Psychiatry and Psychopharmacology (pp. 185195): Springer.

Schutter, D. J., \& Honk, J. v. (2004). Decoupling of midfrontal deltabeta oscillations after testosterone administration. International journal of psychophysiology, 53, 71-73.

Schutter, D. J., \& van Honk, J. (2005). Salivary cortisol levels and the coupling of midfrontal delta-beta oscillations. International journal of psychophysiology, 55(1), 127129.

Suetsugi, M., Mizuki, Y., Ushijima, I., Kobayashi, T., Tsuchiya, K., Aoki, T., \& Watanabe, Y. (2000).

Appearance of frontal midline theta activity in patients with generalized anxiety disorder. Neuropsychobiology, 41(2), 108112.

Thatcher, R. W. (1998). Normative EEG databases and EEG biofeedback. Journal of Neurotherapy, 2(4), 839. 